\title{
Correspondence
}

\section{Consultant psychiatrists who retired prematurely in 1995 and 1996}

Sir: Professor Kendell and Alison Pearce address the issue of early retirement of experienced consultant psychiatrists, attributing it mostly to changing working conditions and loss of professional influence in the running of their services (Psychiatric Bulletin, December 1997, 21, 741-745). We would add that it is likely that many of these colleagues were suffering from burn-out (Guthrie \& Black, 1997). The Psychiatric Committee of the North Thames Region recently asked a group of us to outline areas where working conditions could be improved in order to prevent early retirement and burn-out, and we produced the following 10 recommendations.

(a) Time for reflection and peer discussion, in order to arrive at proper decisions. The job must be manageable, with a measurable clinical workload. Recognition that catchment area sizes do not reflect workload, and medical manpower should be determined by actual clinical demand for psychiatric expertise (Fagin et al, 1995).

(b) Peer support - regular formal and informal meetings with colleagues to share clinical cases and management concerns. Clinical audit as a tool to improve standards and analyse effective clinical practice, not simply to measure performance in managerial or financial terms. Informal occasions to meet over lunch, with the provision of a staff restaurant.

(c) To institute formal internal supervision arrangements, recognising the value of mentors.

(d) To enhance personal and professional development. Ensuring a guaranteed Continuing Professional Development budget, yearly opportunities to attend a major psychiatric conference and an external course and access to a good, local postgraduate library. Leaves should be supported by locums.

(e) To introduce sabbaticals, six months for every five years of continued employment, supported by adequate locum arrangements.

(f) A session a week to pursue research interests and practical encouragement to introduce innovations. Links with an academic department of psychiatry, fostering joint research projects and medical student attachments.

(g) Clear limits and boundaries of professional responsibility, defined in the original contract of employment. Change of workload and responsibility must only be implemented following consultation and agreement with consultants concerned. If there is extra workload planned, added manpower resources should be identified or some current responsibilities dropped.

(h) Up to $10 \%$ of consultant time should be spent on paperwork and bureaucracy. helped by direct access to computer networks.

(i) Support by personal secretary and provision of adequate office space.

(j) Firm opportunities to influence the shape and development of future services, with management commitment to use clinical advice.

Fagin, L., Hollander, D. \& Weller, M. (1995) The consultant's caseload: a working framework. Psychiatric Bulletin, 19, 532-535.

GUTHRIE, E. \& BLACK, D. (1997) Psychiatric disorder, stress and burnout. Advances in Psychiatric Treatment, 3. 275-281.

LEONARD FAGIN, Consultant Psychiatrist and Honorary Senior Lecturer, Forest Healthcare Trust, South Forest Community Mental Health Centre, 21 Thorne Close, Leytonstone E11 4HU; KEVIN HEALEY, Consultant Psychotherapist, Cassel Hospital, 1 Ham Common, Richmond. Surrey TW10 7JF, and DAVID SUMNER, Consultant Psychiatrist, West Herts Community Health Trust, Albany Lodge, Church Crescent, St Albans A13 5JF

Sir: The questionnaire survey of recently retired consultant psychiatrists (Kendell \& Pearce, Psychiatric Bulletin, December 1997, 21, 741745) was both timely and enlightening, and probably contained views held by many who continue to practice. Many respondents to the survey were clear that nothing would have returned them to practice once their decision to retire had been made.

I wish to offer further analysis of the situation regarding unfilled posts since I believe that, although early retirements have increased the risk of 'exsanguination' of psychiatric services in some areas, more problems regarding unfilled vacancies may have arisen due to movement of consultant psychiatrists between posts. 